\title{
REVIEWS.
}

\section{FUNDAMENTALS OF} ANATOMY.

By Carl C. Francis, A.B., M.D. Henry Kimpton. 1937. Price 12/6.

This volume is accurately described as the "Fundamentals of Anatomy" and as such can be most warmly recommended to the junior medical student, the nurse and even to the intelligent layman so direct and simple is the language. The purpose of a particular tissue or organ is always discussed as a preliminary to a description of its structure and in this way an interest is aroused in the subject which should go a long distance in rebutting the too frequent statement that anatomy is a dry-as-dust study and simply a feat of the memory.

The book is profusely illustrated by pictures in colour as well as in black and white, there is a most comprehensive index and, in addition, a good glossary which should be of great assistance to the young or inexperienced reader.

\section{POST-GRADUATE SURGERY.}

By Rodney MaIngot, Vol. III. Medical Publications. 1937. Price 70/- per volume.

The third volume of this text book is devoted to hernia, eye, ear, nose and throat, pharynx, larynx, œsophagus, diaphragm, endoscopic methods, jaws, teeth, tongue, plastic surgery, obstetric surgery, cardiovascular and lymphatic systems, venereal diseases, deep X-ray therapy, physical medicine, and orthopædics. It thus covers a very comprehensive field. The section on hernia is well written, and sets out recent teaching to full advantage. The author rightly places the Bassini operation in the museum and describes a method of operating on inguinal herniæ with silk ligaturesa method we have not used heretofore. Every surgeon, however, has his own particular operation to which he gives preference.

One hundred and thirty pages are given to plastic surgery, which receives very full consideration. Such procedures as taking the wrinkles out of the forehead, removing skin from baggy eyelids, beautifying the breast by raising the nipple, and partial mamectomy together with face lifting appear for the first time in a British text book of surgery and are given much space. The author has, however, omitted to describe the operation for removing fat from the buttock and from the anterior abdominal wall. Little guidance is to be found as to the measures and precautions to be taken to avoid keloid formation, the one bugbear of the plastic surgeon. The operation advocated for the closure of the hard and soft palate is a recently-described and untried modification of Veau's excellent technique.

In the chapters on the lymphatic system, much undue prominence is devoted to the lymphatic permeation theory of the spread of carcinoma. The concensus of opinion among pathologists in London to-day is not to accept this theory in toto. Lymphatic spread does occur but it is believed that the more usual mode of spread of carcinoma to distant parts is by embolism-either carried by the blood stream or by the lymphatics.

The book is full of really excellent material, and the points raised above are minor ones. The work on the tongue is a section which stands out on account of its merit as does that dealing with the operation on the eyes.

We can heartily recommend this book to all surgeons and especially to those Empire builders who are going out into the world away from contact with colleagues, and who will necessarily find themselves alone on the surgical raft.

\section{THE BRITISH ENCYCLOP EDIA OF IMEDICAL PRACTICE.}

Edited by SiR Humphry Rolleston, Bt., G.C.V.O., K.C.B. Vol. 5 (Endoscopy of Respiratory Tract to Goitre), Vol. 6 (Gonorrhœa to Hydrotherapy). Butterworth Medical Publications. 1937. Price $35 /-$ per volume.

These two volumes maintain the high standard set by their predecessors and they convince one more than ever that the complete encyclopædia will be a most valuable addition to the library of every medical man.

The comprehensiveness of the work is very well revealed in volume 5 , treating as it does of such a wide variety of subjects in so many fields of medicine, e.g. diseases of 
the eye, of the foetus and of the gallbladder; tropical medicine (filariasis and flukes); war gases and their effects; food and food poisoning; exhibitionism and mental fatigue; and medical ethics, and the up-to-dateness of the information is exemplified by the important first article on endoscopy of the respiratory tract.

In volume 6 heart disease falls to be discussed and is fully dealt with in all its various aspects. Further subjects included in this volume are gout, hernia, hæmorrhagic diseases and heredity. That the editors have spread their net as widely as possible and given the production an Imperial character is shown by an article on hæmatemesis by Prof. Carmalt-Jones of Otago, one by Prof. Falconer of Cape Town on malignant endocarditis, one by Prof. Dew of Sydney on hydatid disease and still another on heat stroke by Dr. Marsh of Abadare.

We should also mention again the perfect system of indexing so that information sought can be easily found and that the general appearance of the volumes (so far as type, illustrations and binding are concerned) is a credit to the authors, editors and publishers.

\section{THE HAIR AND SCALP.}

By Agnes Savill. Second edition. Illustrated. Pp. 307. Edward Arnold \& Co. London. 1937. Price 12/6 net.

That a second edition of "The Hair and Scalp" should have been necessary after two years is a strong testimony to the value of this book which appeals not only to the medical profession and to those specially concerned with skin diseases but to hairdressers, and all interested in the growth and culture of the hair and in the diseases which may affect it.

In the second edition the text has been partly re-written and some 20 pages of new matter added. The chief reason for the popularity of this book is that it is seriously written and shows evidence throughout of a wide study of the literature on the subject and of the close observation and shrewd reasoning of the author.

The anatomy, physiology and diseases of the hair are described in detail and the text is adequately illustrated by photographs of diseased conditions and histological preparations. Among other interesting and important observations the author refutes the timeworn fallacies that cutting, shaving and the application of greasy preparations stimulate hair growth, is unable to find any scientific proof of the value of singeing the hair, stresses the danger of attempting to cure hypertrichosis by exposure to radium or the $\mathrm{X}$-rays, and in connection with hair dyeing considers that there is no dye which is permanent and efficient and yet free from the danger of causing dermatitis.

On the whole the book is so well written and contains such a wealth of information that the second edition cannot but be as welcome and successful as its predecessor.

\section{DISEASES OF THE SKIN.}

By Robert W. MacKenna. 4th Edition, revised by RoBert M. B. MacKenna. Pp. 558 with 168 illustrations and 46 coloured plates. Baillière, Tindall and Cox. London. 1937. Price 20/- net.

It was in 1923 that this text-book on skin diseases from the pen of the late Dr. Robert W. MacKenna was published. A second edition appeared in 1927 three years before his death. A third edition by his son Dr. Robert M. B. MacKenna followed in 1932 and this in turn by the present edition.

That a fourth edition has been called for in less than 15 years is a tribute to the merits of the book. As was to be expected from a versatile author of a well-known novel the original text is lucidly and interestingly written. It is a medium sized text-book, richly illustrated both by black and white and coloured plates, printed on smooth paper which shows up the photographs admirably, with the text in two sizes of type according to the relative importance of the matter. Of the text-books in this country it is somewhat comparable in size to Sequira's "Diseases of the Skin."

Every effort has been made in revising the book in the last two editions to avoid changing its original character, and omitting items or making any additions which were not essential to keep it up-to-date. A useful innovation in the present edition is the giving of the approximate metric quantities and percentages as well as the apothecaries weights and measures in prescriptions, 